\title{
Technologies Frequently Used by Elementary Principals
}

\author{
Alejandro Garcia*, Jesus Abrego, John Jauregui \\ Department of Organization and School Leadership, College of Education, University of Texas Rio Grande Valley, United States
}

Copyright $(2019$ by authors, all rights reserved. Authors agree that this article remains permanently open access under the terms of the Creative Commons Attribution License 4.0 International License

\begin{abstract}
Technology continues to be a driving force for change in instructional practices. Principals have transitioned from managers to instructional leaders that support innovative technology practices. This study sampled 30 elementary school principals' technology usage from two school districts and focused on discovering the hardware and software used directly by the elementary principals and how they learned to use those technologies. Data analysis from the online questionnaire and the interviews revealed that the elementary principals used technology predominately for administrative purposes. All the elementary principals surveyed reported that the type of software applications used by them on a daily basis consisted primarily of : web based data analysis tools such as Euphoria Aware, Workshop, Forethought, web based Public Education Information Management System (PEIMS), and productivity tools in the form of word processing, spreadsheets and presentation applications. The amount of time on a daily and weekly basis outweighed time and effort they put in to technology for instructional purposes. Results from the interviews indicated that these elementary principals all had smart phones, which enabled them to view the Internet, use social media and send and receive e-mail messages. In addition, $75 \%$ elementary principals surveyed reported learning the technologies on their own with some support from their district's technology support staff.
\end{abstract}

Keywords Elementary Schools, Principal Technology Leadership, Technology Integration and Technology

\section{Introduction}

A principal's use of technology will transmit the importance of technology to both staff members and students. Holland and Moore-Steward [1] remarked that the principal needs to model and support technology applications in meaningful activities. It is doubtful that simply transferring from pencil and paper worksheets to digital formats will bring about improved student achievement. Principals who are technology leaders comprehend that when properly used at schools, technology will enhance teaching and learning in the classroom. These kinds of principals can provide the added support and direction teachers are looking for [4]. It was revealed in a study by Eren and Kurt [2] that there "...was a significant difference between the school principals' leadership behavior regarding the supply and use of educational technologies and their receiving training on word processing, the Internet and e-mail, school management technologies, and databases," (p. 631).

Technology in its many uses has become omnipresent and inescapable. With contemporary society, embracing a multitude of forms of technology, technology's presence and dominance in our daily lives has become ubiquitous. Webber [3] stated that, "...technology pervades almost everything in our lives-online banking, shopping, text messaging, movies-on-demand, coordinated traffic flow, light rapid transit scheduling, mobile telephone networks, climate control systems, and medical information access".

Due to the large presence of instructional technology hardware and software in public schools, "school districts throughout the country increasingly demand that effective leadership in the area of instructional technology come from insightful and forward thinking school leaders" [4]. Therefore, it is imperative that all principals become well-versed in both using and evaluating technologies on their campuses. Dawson and Rakes [5], found that principals determined the extent of technology integration in the classroom. In short, they are the chief technology leaders for their campus.

\section{The Purpose of the Study}

The purpose of this qualitative phenomenological study is to describe the daily and weekly software and hardware, social media usage used by elementary principals and how they are trained to use them from a sample of three school districts located in south Texas.

\subsection{Literature Review}

\subsubsection{Principal's Personal Use of Technology}

Principals as role models and technology leaders should use various technologies on a daily, weekly, and monthly 
basis. Gibson [6] stated that principals should have a personal proficiency of technologies and concentrate their efforts on understanding how technology can be used to promote their school vision, mission and culture while promoting teaching, learning and management. By doing so, principals are demonstrating to teachers that technology can be both a powerful administrative and instructional tool.

In a study by Afshari et al.,[7] the data analysis revealed that 43.3 percent of the principals use computers 2 or 3 times a week, while only $6.7 \%$ of them used computers on a daily basis for conducting their tasks. The data also revealed that principal's computer use centered on four domains: "Internet use, hardware and software use, instructional use, and administrative use" p. (85).

In terms of Internet usage, Afshari's et al., [7] study indicated that the majority principals used the Internet daily at school rather than at home. It was revealed that principals' daily Internet use consisted of receiving and sending e-mails and conducting web searches. The principals reported that in their web searches they explored educational or professional web resources just a few times a month.

Concerning hardware and software use, Afshari's et al., [7]study reported that $60 \%$ of the principals used word processing on a daily basis, while only $3 \%$ reported using other productivity tools such as spreadsheets, databases and presentation tools. Afshari et al., [7] pointed out that principals expressed a lower proficiency in productivity tools such as spreadsheets and database tools, since they require the critical skills of data manipulation and interpretation. Afshari et al., [7] concluded that principals should understand word processing, how to construct and report from a data base, how to use a spreadsheet to solve financial problems, how to create reports and link them with a mail-merge package, how to create and maintain files on a disk, how to use hardware available in their district, and how to use specific applications programs in use in their school (p.88).

On the topic of computer instructional use, the majority of principals in Afshari's et al., [7] study reported that they primarily used the computer for, "recording discipline referrals, monitoring student achievement for specific objectives, monitoring students' grades, creating a master schedule, and developing or writing curriculum" (p.86).

Of the four areas of technology use, administrative use was the least reported category. Approximately $23 \%$ of the principals indicated that they used computers 2 to 3 times per week for these tasks [7]. Principals stated that the administrative tasks included using computers to communicate with the state or collaborating with colleagues.

Afshari et al., [7] recommended that principals be skilled in balancing the instructional and the administrative computer tasks, while encouraging technology's role in the teaching and learning process. In addition, it was recommended for successful adoptions, principals must continue to be supportive role models [8].

\subsubsection{Technology Preparation for Principals}

Kruse and Buckmiller [9] remarked that principals should be able to use technology to improve students' education by support from technological innovation and integration. Holland and Moore-Steward [1] remarked that supplying a source of capable school leaders in the technology-rich climate of today's schools must become a priority for higher education institutions and school districts. Holland and Moore-Steward [1] viewed the principal as a technology leader in the effort to infuse technology into the school; therefore, technology training for principals, as well as for teachers, should be a priority. Kelley, Kinard, and Hope [10] argued that, "Professional development to use computer technology is an essential part of its integration into schools. Without training that focuses on technology and how it can be made a part of the work and learning environment, computer technology will not be used to its potential" (p. 476). As affirmed by Kelly, Kinard and Hope [10], principals and others will not be fully conscious of the rewards that technology can offer without professional development.

A lack of instructional technology skills may be a result of the fact that most professional development efforts have focused on the needs of the classroom teachers, with little attention being paid to administrators' needs. Along those lines, Schrum, Galizio and Ledesma's [11] findings agree that not much energy has been devoted to giving principals an appropriate amount of technology professional development that will allow them to become stronger technology leaders. Schrum, Galizio and Ledesma[11] stressed that without adequate preparation, principals would not be able to become effective managers of technologies.

It is the main responsibility of institutions of higher education to train and prepare principals and other administrators in the use of technology. University educational leadership programs are not providing the technology training needed for today's public school leaders. Conventionally, university-based educational leadership curriculum have overly stressed management and administrative issues rather than instructional issues [3]. The quality of our principals and other administrators is highly reliant upon the quality of the university-based leadership preparation programs [12]. Rakes and Dawson [3] agreed that more principals than not have been inadequately trained or acquired firsthand knowledge in the use of technology. Hope, Kelley and Kinard, [10] have confirmed that principals have technology training needs that have not been addressed. This has resulted in principals facing the daunting challenge of leading schools through a change process without adequate technology knowledge and skills [3]. This self-training has resulted in minimal instructional technology proficiencies for 
principals. Although some university-based leadership preparation programs do provide a course on technology, some students reported that such course did not address areas of technology leadership in curriculum [12].

Conversely, schools whose principals received technology integration training had higher levels of technology integration than a control group [3]. "The more sustained the principal's training experiences and the more those experiences are tied to the school's curriculum and to the principals' needs, the more progress the school is likely to make toward technology integration" [3, p. 45.] Although principals are the leading role models on their campus in a multitude of areas, many principals express concern and point out that they are too busy with other demands of their job $[10,13]$. At some point in time, it will become a priority for principals to redirect their attention to familiarize themselves with technology, which can assist them in carrying out their duties and then applying it on a regular basis [10]. Hope, Kelly and Kinard believed that, it is essential for principals to develop a strong familiarization with and understanding of the capabilities, limitations, and benefits of computer technology in order to promote instructional technology's integration in schools. Hope, Kelley and Kinard [10] stated that there is no doubt that principals can profit from professional development to use technology., "The fundamental assumption is that knowledge and proficiency in technology and applications of technology in education are essential to effective instructional leadership, expert decision-making and competent management" [10, p.515]. The void in technology professional development for principals makes it hard for administrators to make prudent decisions and to understand the process of implementing technology.

What is missing from the current literature are more empirical studies that examine the habits and types of technologies used by elementary principals. Hence, the purpose of this paper is to investigate, from a sample of elementary principals' own perspectives, types and frequency of technologies used.

\subsection{Theoretical Framework}

The theoretical framework for this is study is based upon Adult learning theory as outlined by Knowles [14]. Adult learning theory advanced the following six assumptions:

1. As a person matures, his or her self-concept moves from that of a dependent personality toward one of a self-directed human being.

2. An adult accumulates a growing reservoir of experience, which is a rich resource for learning.

3. The readiness of an adult to learn is closely related to the developmental tasks of his or her social role.

4. There is a change in time perspective as people mature-from future application of knowledge to immediacy of application. Thus, an adult is more problem centered than subject centered in learning.
5. The most potent motivations are internal rather than external

6. Adults need to know why they need to learn something, [26]

The first assumption, being a self-direct learner, emphasizes that adults prefer to plan and direct their own learning. A great deal of self-autonomy or control is desired by the adult learner. Adult learners as a whole thrive on directing themselves [15]. Adult learners also desire to take upon responsibility for their learning $[15,16]$. Older learners sometimes resent not having that sense of responsibility and don't want to be treated like younger students.

In the second assumption, accumulating a growing reservoir of experience, Knowles [14] explains that adults bring with them a broad set of experiences and knowledge such as previous education or work social experiences [15]. Adults scaffold their previous knowledge to build upon tasks that are new. This enables adults to learn tasks easily and quickly.

The third assumption centers on that idea that adults are not ready to learn until they sense an urgency for new knowledge. This sense of urgency could be due to a change in life experiences such as a death of a loved one, change of employment or the birth of a child. This sense of urgency or change of life circumstances is the trigger for an adult's readiness to learn. In essence, adult learners are goal oriented.

The next assumption, being problem centered, is closely tied to the readiness to learn. This fourth characteristic of adult learning is trigged by a need or motivation to learn a new task that is an immediate problem. Adult learners apply their focus to find a relevancy of application. This shift in real life and time of priorities in performing a task, solving a problem or increasing their satisfaction is a strong factor in motivating adults to want to learn [14].

In the last assumption, internal motivation, Knowles [14] states that adult learners are more intrinsically motivated to learn. As in the previous assumption, this internal motivation may be tied to a sense of urgency to solve a real live problem [15]. Motivated learners remain interested longer and find the rewards to learning more meaningful.

\section{Methodology}

The methodology of this study will take a phenomenological qualitative approach. According to Creswell [17] phenomenology qualitative research aims to create newer understanding of the lives of research subjects by depending upon the participants first hand interviews. Reality is constructed by the participants themselves, and it is the aim of qualitative research to create understandings of the experiences of the participants. What is of upmost importance is to document and construct meanings from the participants' views and not of the researchers [18]. 
There are two types of phenomenology: hermeneutical and transcendental phenomenology. Hermeneutical phenomenology focuses more on the researcher. The researcher selects a phenomenon and look at the themes that resulted from the experience [17]. The researcher then interprets the themes and writes the meanings behind the phenomenon. On the other hand, the transcendental phenomenology requires the researcher to detach themselves from the phenomenon. This type of approach requires the subjects, who share the same phenomenon, are to be the center of the research [17].

The transcendental phenomenology approach by Moustakas [19], adapted from Husserl, focuses on the participants' given descriptions to generate an essence of the lived experience, as opposed to hermeneutical phenomenology which more strongly relies on the researcher's interpretations of what lived experience means [19]

In addition, textural descriptions will also be used to help clearly explain the phenomenon to the reader and give them a sense of what it would feel like to be experiencing that same phenomenon and the locations of where they occurred. In this study, the phenomenology used will be the transcendental phenomenology, where the researcher will detach from the research and will focus on the subjects. In the case of this study both interviews and a questionnaire were used to explore the elementary principals' technology habits.

\section{Sampling Procedure}

Selection of the participants in this study was conducted by purposive sampling. This sampling method seeks to select the cases to be included in the sample "...on the basis of their judgment of their typicality or possession of the particular characteristics being sought" [20, p. 114]. In the case of this study, the selected sample of elementary principals was from three mid-sized school districts that have reported utilizing technology. Therefore, this sample includes elementary principals who are able to report first hand their experiences with technology on a daily, weekly and monthly basis. According to Cohen et al., [20], "there is little benefit in seeking a random sample when most of the random sample may be largely ignorant of particular issues and unable to comment on matters of interest to the researcher (p.115).

\subsection{Sample Population and Setting}

For phenomenological studies, Creswell recommends 5 -25 participants [17]. The participants for this study were elementary principals from three school districts located in South Texas Areas. School district "A", currently has 19,000 students and 11 elementary schools districts. School district " $\mathrm{B}$ " is a neighboring school district with approximately 15,000 students and 14 elementary schools. The third school district, "C" has 34,000 students and 31 elementary schools. Thirty out of the 56 possible elementary principals agreed to participate in the research study. Of the 30 participants, 26 were female with 4 male elementary principals. From the 30 participants 19 elementary principals had a total of 15 or more years as elementary principals. Two participants had 10 years of experience, while the remaining 9 participants has 5 or less years as elementary school principals. Sixteen of the 30 elementary principals were between 41 to 50 years old, while 10 participants reported their age as 51 to 60 years old. The remaining elementary principals were 31 years old or younger.

\subsection{Data Collection Procedures and Instrumentation}

After obtaining permission from three school district superintendents to survey their elementary principals' the researcher e-mailed the link to an online questionnaire, which assessed the sample of elementary principals' technology use and training. A total of 30 of 56 elementary principals responded to the online questionnaire. At the end of the questionnaire was a link soliciting participation in an interview. Out of the 30 participants, 25 elementary principals agreed to be interviewed further for clarification. Each interview consisted of 5 open ended questions and were audio recorded for ease of data analysis.

\subsection{Research Questions}

1. Which hardware and software applications are commonly used by elementary principals on a daily and weekly basis?

2. What type of social media does the elementary principal use?

3. What type of student progress reports do elementary principals access?

4. How were the elementary principals trained to use the technologies?

\subsection{Data Analysis}

"Qualitative data analysis involves organizing, accounting for and explaining the data; in short, making sense of data in terms of the participants' definitions of the situation, noting patterns, themes, categories and regularities" [20, p.461]. Miles and Huberman described qualitative analysis as a continuous, repetitive process that consists of the following components: data reduction, data display, and conclusion-drawing and verification. Data reduction commonly refers to choosing, centering, streamlining, and conceptualizing and converting the data into meaningful language. The second component, data display is an organized compacted gathering of information that allows the researcher to form conclusions. Lastly, conclusion-drawing and verification, involves making decisions from the data of the meaning of things 
and how that data tested for validity [21].

In this study, the data was reduced by downloading the questionnaire results it into a comma separated value file and importing it into SPSS for data analysis. Descriptive statics was used to gather demographic and frequency data. For the second data source, the interview data audio recordings were downloaded into a computer and transcribed into nVivo for analysis. The researcher then began the analysis to identify common phrases, patterns, and relationships among the interviews and participants and developed codes. In order to ensure the transcription process was reliable, the researcher a listened to the interviews two times.

Qualitative data analysis is the process of making sense out of one's data [18]. It involves preparing the data for analysis, conducting different analyses, moving deeper and deeper into understanding the data, representing the data, and making an interpretation of the larger meaning of data [22].

Data display was accomplished after the coding and analysis of the transcriptions from the audio-recorded individual interviews. Afterwards the conclusion-drawing and verification was accomplished by the following methods: member checking and peer review of the data. Member checking provides credibility by having the participants review the data and its analyses to check the accuracy transcriptions [23].This will also allow the participants to conduct member checks and avoid having the researcher's bias to influence what the participants discuss in the interviews [24]. In this study, once the participants were interviewed, they were given an opportunity to review the transcripts. The researcher contacted interviewed participants via e-mail and then solicited comments or clarifications they felt were necessary to ensure the accuracy of their responses.

The second method that was used to establish validity, peer review, is used to improve the accuracy of the story. "This process involves locating a person who reviews and asks questions about that qualitative study, which the account will resonate with the people other than the researcher" [22, p. 196]. This person should be a noninvolved professional with whom the researcher can hold both critical and candid conversations [25]. In the case of this study a peer reviewer reviewed the results of the online questionnaire and interview transcripts. The peer reviewer in this study also listened to the researcher's thoughts on the meaning of the collected data and provided feedback on the soundness of the researcher's analysis.

\section{Results/ Findings}

\subsection{Research Question 1: Technologies Used by Elementary Principals}

In response to the first research question, "Which technology applications and hardware are commonly used by elementary principals on a daily and weekly basis?, data analysis from the online questionnaire and the interviews revealed that the elementary principals used technology mostly for administrative purposes. The amount of time on a daily and weekly basis outweighed time and effort they put in to technology for instructional purposes.

The administrative purposes included the following tasks: communicating with stake holders via e-mail, keeping track of their meetings via their e-mail calendar, running student achievement data reports, monitoring students' grades and attendance, managing the campus budgets, approving purchase orders and campus maintenance, creating memos, presentations and meeting agendas, reading and posting messages on social media and appraising teachers and staff.

Conversely all 30 elementary principals explained that their instructional technology usage consisted of primarily of running student software usage reports such as I station, Accelerated reader and Think Through Math. The majority of the elementary principals indicated that software selection was primarily done with collaboration from Campus Administrators, Curriculum Specialists from central office, Librarian/Media Specialists, and Teachers

\subsection{Technology Hardware and Software Applications Used Daily}

Data analysis from the online questionnaire revealed that out of the 30 elementary principals $60 \%$ of them listed their cellular phone as a primary technology used. Results from the interviews indicated that these elementary principals all had smart phones, which enabled them to view the Internet, use social media and send and receive e-mail messages. Seven of the 8 remaining principals used a device such as a tablet, laptop or desktop on a daily basis, while only one used a Web-enabled watch (Apple watch) on a daily basis.

Table 1. Hardware used on a daily basis

\begin{tabular}{cc}
\hline Hardware type & Percentage of Participants \\
\hline Cell phone (smart phone) & $60 \%$ \\
\hline iPad/Tablet & $20 \%$ \\
\hline Laptop/Desktop & $10 \%$ \\
\hline Web-enabled watch & $10 \%$ \\
\hline
\end{tabular}

All the elementary principals surveyed reported that the type of software applications used by them on a daily basis consisted primarily of : web based data analysis tools such as Euphoria Aware, Workshop, Forethought, web based Public Education Information Management System (PEIMS), and productivity tools in the form of word processing, spreadsheets and presentation applications. In terms of analysis of student achievement, $100 \%$ of the principals in this study used Euphoria Aware to provide them vital student achievements statistics. According to the 
principals, this software allows them to drill down and perform an item analysis. In addition, as part of this suite, principals used Euphoria Workshop to keep track of their teachers' staff development and Forethought to review teachers' lesson plans. One principal explained that, "using technology was a powerful management tool." She wondered how other principals survived, without the use of technology. Another principal stated that, "utilizing technology for data analysis was easier and quicker than doing by hand calculation." Another principal, Dolly (pseudonym), reported that, "it was an important management tool for disaggregating data."

Overall, $100 \%$ the principals in the study depended upon data desegregation and data analysis to examine their different student populations.

All the elementary principals also reported using Internet browsers such as Internet Explorer to utilize web based software applications such as the Public Education Information Management (System (PEIMS). PEIMS "encompasses all data requested and received by The Texas Education Agency about public education, including student demographic and academic performance, personnel, financial, and organizational information" [25]. These principals stated that they used PEIMS portal primarily to access and manage their budgets, view student data such as demographic, school leaver, attendance and discipline.

In addition to using the Internet for data analysis, all of the principals in the study stated that relied upon Internet searches to locate important technologies. For example, Betty (pseudonym) stated that, "I do use technology via the Internet and I do a lot of research and its 2 important for me to me to keep up". She also reflected that, "...I use the Internet all the time to look up current information."

In addition, all the principals in this study used productivity tools such as word processing, spreadsheets and presentation tools. One principal reflected that, "my job has been made a lot more automated with the available of online productivity tools such as G suite."

Table 2. Software applications used on a daily basis

\begin{tabular}{cc}
\hline Software & Percentage of Participants \\
\hline Data Analysis & $100 \%$ \\
\hline Internet Browser & $100 \%$ \\
\hline Productivity Tools & $100 \%$ \\
\hline
\end{tabular}

\subsection{Technology Hardware and Software Applications Used Weekly}

In terms of hardware used on a weekly basis $100 \%$ of the elementary principals revealed that they continued to use their smart cellular phones and desktop PCs to access their e-mail for quick correspondence and to conduct brief queries on websites on a weekly basis. Ninety percent stated that their laptops were more convenient for composing longer e-mails, memos, managing spreadsheets and creating presentations. Eighty percent explained that they used IPad or tablets for the same functions as their laptops. Forty-five percent stated they had access to digital cameras to document special events on their campus. Susie, Erica and Betty ((pseudonyms) explained that they "used their cellular smart phones for that purpose as well." Other hardware that was seldom used by the elementary principals included Web enabled watches, $\mathrm{mp} 3$ players, Activity trackers (Fit Bit) and eReaders.

Table 3. Hardware used on a weekly basis

\begin{tabular}{cc}
\hline Hardware type & Percentage of Participants \\
\hline Cell phone (Smart phone) & $100 \%$ \\
\hline Desktop PC & $100 \%$ \\
\hline Laptop & $90 \%$ \\
\hline iPad/Tablet & $80 \%$ \\
\hline Digital Camera & $45 \%$ \\
\hline Web-enabled watch & $25 \%$ \\
\hline MP3 Players & $25 \%$ \\
\hline Activity Tracker & $15 \%$ \\
\hline e-Reader & $15 \%$ \\
\hline
\end{tabular}

One hundred percent of the elementary principals stated that they continued to use data analysis software such as Euphoria Aware and Euphoria Forethought (Lesson Planner) on a weekly basis. Erica (pseudonym) stated that, "data reports assisted her by allowing them to group their students. And view the data in the form of charts and graphs." Seventy-five percent of the elementary principals replied that they continued to use the PEIMS web-based applications to manage budgets and to view student demographic, school leaver, attendance and discipline data on a weekly basis. Fifty percent of the elementary school principals also reported using other web-based applications for student achievement such as Sungard and Prologic. Seventy percent indicated they continue to use Microsoft office productivity tools on a weekly basis. In addition to Microsoft office productivity tools, $50 \%$ also exclaimed that they used G-Suite, which are tools from Google Education. Susie (pseudonym) explained that, "using G-Suite web based tools allowed them more freedom to work away from their desks and offices, since it provides web solutions that allow them to store and share files, create documents, spreadsheets and presentations."

Table 4. Software applications used on a weekly basis

\begin{tabular}{cc}
\hline Software Applications & Percentage of Participants \\
\hline Eduphoria & $100 \%$ \\
\hline PEIMS & $75 \%$ \\
\hline Microsoft Office Suite & $70 \%$ \\
\hline Sungard & $55 \%$ \\
\hline G-Suite & $50 \%$ \\
\hline E-School & $50 \%$ \\
\hline Prologic & $30 \%$ \\
\hline
\end{tabular}




\subsection{Research Question 2: Social Media Used}

Research question two asked, "What type of social media do elementary principals access? The data from the survey revealed that $55 \%$ of the elementary principals used campus based rather than personal Facebook accounts. Facebook is a popular social media tool that can be accessed from a large range of devices with Internet connectivity, such as desktop computers, laptops and tablet computers, and smartphones. Users can create a customized profile and add other users as friends, exchange messages, post status updates, share photos, videos and links. Julia (pseudonym) remarked that she “....had posted photos of teachers and students, videos and school events such as awards assemblies and celebrations." The principals explained that this was a popular way to stay connect to both parents and community members since it was a way to celebrate positive accomplishments. In addition to Facebook, $40 \%$ of the elementary principals used Instagram as well. Instagram is a photo and video-sharing social networking service. Similar to Facebook, users can upload photographs and short videos, follow other users' feeds, and geotag images with the name of a location. Susie (pseudonym) explained that, "users can connect their Instagram account to other social networking sites, enabling them to share uploaded photos to those sites." Instagram introduced hashtags to help users discover both photos and each other. The elementary principals explained that Instagram allows users to make tags specific, rather than tagging generic words like photo, to make photographs stand out and to attract compatible Instagram users. The elementary principals expressed that they used Instagram primarily for posting of photos and videos.

Another form of social media used by the elementary principals is SnapChat. SnapChat is a multimedia messaging application that makes photos pictures and messages usually only available for a short time before they become inaccessible to users. Snapchat allows users to edit their photos by including a variety of filters and effects, text captions, and drawings. Thirty percent of respondents reported that they use Snap Chat primarily for personal uses, and seldom did they use it for professional aims.

Twitter, on the other hand was, used for professional reasons by $25 \%$ of the elementary principals; and they found it very valuable for sharing information and resources. Twitter which is online news and social networking service on which users post and interact with messages known as "tweets". Tweets were restricted to 140 characters, but after November 2017, this limit was doubled for all languages except Japanese, Korean, and Chinese. The elementary principals exclaimed that they used Twitter hashtags, those words or phrases starting with a \#, to organize conversations by topic. This allows parents and community members to easily search for pertinent topics on the school's Twitter website. Julia (pseudonym) also explained that, Twitter allowed her to: "post very concise messages in real time about what teachers and students are experiencing in classrooms, in extracurricular activities, or in service learning projects; create a window into the world of their schools; highlight teachers by recognizing accomplishments; and share daily words of wisdom to stakeholders."

Lastly, only $10 \%$ of the elementary principals sampled in this study reported not using any form of social media. Erica, Betty, Sandy and Julia (pseudonyms) stated that some of the reasons for not using them varied such as "not having enough time, being fearful of the consequences of using messages that would be taken out of context, and a lack of training."

Table 5. Social Media used

\begin{tabular}{cc}
\hline Social media type & Percentage of Participants \\
\hline Facebook & $55 \%$ \\
\hline Instagram & $40 \%$ \\
\hline Snapchat & $30 \%$ \\
\hline Twitter & $25 \%$ \\
\hline No social media used & $10 \%$ \\
\hline
\end{tabular}

\subsection{Research Question 3: Access of Student Technology Usage Reports}

Research question three asked "what type of student technology usage reports and how often did elementary principals access them?" In response to this question, the data revealed that $100 \%$ of the elementary principals in this study accessed iStation student usage reports. iStation provides computer-based assessment and instruction in reading and writing for PreK-12 students where students complete game-based lessons and activities led by animated characters. Istation begins with the game-like Indicators of Progress that determines each student's reading level and adjusts in length and difficulty in real-time based on student performance. The program uses assessment data to generate an individualized learning path for reading instruction. The principals in this study indicated that the reports: identify students for small-group instruction, student's performance, usage details, Lexile measure, percentile rank, grade equivalency, and summarize campus assessment results, which includes skill growth by tier.

In addition to iStation, $80 \%$ of elementary principals reported that they also ran Think Through Math reports. They stated that their students used Think Through Math as supplemental math curriculum that adapts to the unique needs of each student and aides students to move to the next level of mathematical skills. Furthermore, they went on to say that Think Through Math is adaptive, so students learn in their zone of proximal development with the right degree of challenge.

The next widely used software usage report reported by the elementary principals in this study was RAZKids. Seventy percent of the respondents used it on their campus 
because it provides both Spanish and English reading comprehension support along with providing students with electronic tests for reading comprehension. In addition, RAZkids allowed their students to practice reading anytime or anywhere. The elementary principals that used it on their campus explained that viewing the reports was simple and very easy to understand.

The last application, Reasoning Mind was reported as being used by $45 \%$ of elementary principals. They explained that Reasoning Mind is computer-based math curricula and provides professional development to teachers using the program. This application was selected because just like RAZkids, it is a supplemental online software program for students in PreK through first grade that covers the skills and knowledge that are essential to future success in mathematics. The elementary principals also reflected that this application immersed their students in a virtual world which allows them to connect the mathematics they are learning to their everyday surroundings.

Table 6. Student software usage reports

\begin{tabular}{cc}
\hline Software application report & Percentage of Participants \\
\hline iStation & $100 \%$ \\
\hline Think Through Math & $80 \%$ \\
\hline RAZKids & $70 \%$ \\
\hline Reasoning Mind & $45 \%$ \\
\hline
\end{tabular}

\subsection{Frequency of Running Student Software Reports}

In terms of frequency of running student software progress and usage reports, the data revealed that only $10 \%$ from the sample of elementary principals reported running reports on a daily basis. The remaining $90 \%$ stated that reports required some time to run, and they felt that it was unnecessary to run the student progress and usage reports that often. Only $15 \%$ stated they ran these reports two to three times per week. The highest reported frequency revealed that $40 \%$ ran the progress and usage reports on a weekly basis. From this sample, principals echoed that running these reports was important, but anything less than a weekly basis was unproductive. Julia (pseudonym) stated that the time required to $\log$ in and run the multiple software reports was a factor in running them only once per week. Fifteen percent reported that they ran the reports once a month, while 10 percent stated that they ran the reports twice a month. The remaining principals did not run any reports at all. Instead they relied on others to run and analyze the progress and usage reports.
Table 7. Frequency of running Student Software reports

\begin{tabular}{cc}
\hline Software application report frequency & Percentage of Participants \\
\hline Daily & $10 \%$ \\
\hline $2-3$ times per week & $15 \%$ \\
\hline Once a week & $40 \%$ \\
\hline Once a month & $15 \%$ \\
\hline Twice a month & $10 \%$ \\
\hline Never & $10 \%$ \\
\hline
\end{tabular}

\subsection{Research Question 4: Source of Technology Training}

Research question Four asked "How were the elementary principals trained to use the technologies?" The data revealed that $75 \%$ elementary principals trained themselves by "figuring it out." As indicated by the interviews the majority of the respondents felt that due to their schedules, which included early morning and late night sessions, principals took on learning the software applications without relying on anyone else. They also indicated that with so many online help files and videos, it was a lot easier to learn the basics of the software applications that were used frequently. Another source for training was assistance from the school district technology support staff. Sixty-five percent of the elementary principals felt that support staff were just an e-mail or phone call away. Principals revealed that their district technology support staff are very helpful and made frequent visits to campuses. Because of the frequent presence of the district technology support staff, elementary principals got trained on the use of technologies on a daily and weekly basis. The elementary principals also added that they were also more knowledgeable on the hardware and software applications because the district technology support staff attended training themselves and trained teachers. They explained that the district technology support staff are professionals who were formerly classroom teachers and that they used their teaching backgrounds and methods to train the elementary principals.

Table 8. Source of Principal Technology training

\begin{tabular}{cc}
\hline Source of technology training & Percentage of Participants \\
\hline Figured it on my own & $75 \%$ \\
\hline District Technology Support staff & $10 \%$ \\
\hline Campus Technicians & $10 \%$ \\
\hline District Technicians & $4 \%$ \\
\hline Librarian/Media Specialist & $1 \%$ \\
\hline
\end{tabular}


Another source for the elementary principal's technology was from campus computer technicians and district technicians. The elementary principals explained that the technicians are very knowledgeable in hardware but were limited in the instructional, administrative and productivity software as it related to the job of a campus administrator or teacher. The last source that principals reported for technology training was from their campus Librarian/Media Specialist. Fifteen percent of the elementary principals stated that the campus Librarian was very helpful but sometimes was busy with students and staff. They felt that they could not ask them for assistance too often because they did not want to take time away that should be spent on the students or teachers.

\section{Discussion}

Several findings for this study are very compatible with previous research conducted by Afshari et al., [7]. As in Afshari's et al., [7] study, the findings in this study uncovered that the pattern of technology usage for elementary principals were primarily for administrative functions rather than instructional functions. The administrative tasks such as communicating with stake holders via e-mail, keeping track of their meetings via their e-mail calendar, running student achievement data reports, etc. far outweighed the time and effort spent on instructional functions such as progress monitoring and usage of student software. Afshari's et al., [7] study reported that $60 \%$ of the principals used word processing daily, while this study found that principal's three primary daily administrative technology tasks revolved upon data analysis, social media and productivity tools usage.

\subsection{Technologies Used by Elementary Principals}

As daily and weekly consumers of technologies, elementary principals' software and hardware usage is different than that of their teachers. That said, principals as technology leaders should be inspirational motivators that drive others by supplying meaningful challenges to the work of their followers $[26,16]$. As adult learners, both elementary principals and teachers' are goal oriented and driven to solve problems that are relevant to their daily lives [14]. In the case of relevancy for principal and teachers, the aim should be to use technology as a means to an end or as tools to improve instruction. Students typically become excited when they learn by hands on technology activities. Consequently, elementary principals should nurture a passion for the tools that teachers can use on a daily and weekly basis to supplement teaching and learning on their campus. Leaders should intellectually stimulate their followers to become creative innovators by developing innovative ways that address age-old solutions and challenge the status quo. Therefore, elementary principals can be a catalyst for change and promote technology for the teachers. As adult learners, elementary principals are problem centered and are highly motivated when the task is to solve real life problems.

In terms of daily usage, findings in this study also uncovered a heavy dependence on Internet application usage. The elementary principals' patterns of usage consisted of data analysis and social media usage. The elementary principals relied predominately upon the Internet to analyze data, run reports, manage facilities and budgets and communicate with stakeholders via e-mail and social media. Sixty percent of the elementary principals used cellular smart phones, which allowed them to quickly send and receive e-mail and text messages.

In addition to the findings of daily Internet usage, this study revealed that $100 \%$ of principals use hardware such as their Desktop PCs and laptops on a weekly basis, as opposed were different to Afshari's et al., [7]study which revealed that less than half the principals used their technologies 2 to 3 times per week. Principals who on rely daily or weekly usage of hardware and software to solve problems and conduct administrative tasks empower themselves with the proper tools that enable them to become to become school administrators.

\subsection{Social Media Used}

In terms of social media, $55 \%$ of the elementary principals in this study reported using Facebook. Elementary principals felt that connecting to their families and community in a modern way was very important. They felt that by showcasing events and displaying photos and videos of students and teachers, their parents would feel a better sense of community with the school. Other forms of social media such as Instagram, Snapchat and Twitter that have similar features to Facebook were used. Less than $10 \%$ of the elementary principals in this study did not use any form of social media. Reasons stated for non-usage are inexperience with the social media application, fear of accidently posting unwanted materials, and time spent updating content.

\subsection{Student Progress Reports}

Monitoring student progress in the form of software progress and usage reports was another important software task for elementary principals. iStation, which focuses upon reading and writing was given priority on both campuses in this study. Forty percent of the elementary principals felt it was very important to run and analyze the reports at least once per month. Reasons stated were that they felt that weekly reports would not show significant differences and that slow and steady growth would only show up on a longer basis. As technology leaders it's important that they continue to motivate teachers' and students' use of technology in their classroom and 
computer lab settings $[2,4,27]$. Their leadership will make or break any change initiative on campus.

\subsection{Source of Technology Training}

Seventy five percent of the elementary principals in this study reported being self-taught. As adult learners, elementary principals are self-directed goal oriented learners. They also felt that they should take responsibility for their own learning [14]. The elementary principals in this study indicated that most of their daily duties were away from their desks, and they could not receive assistance during early and late hours to learn hardware or software. On some occasions, $65 \%$ of the elementary principals reported district technology supports were available to help them since they were already on campus to help the teachers.

\section{Conclusions and Implications}

Principals are an integral part and are at the forefront of any change initiative on their campus [28]. As leaders, principals should promote and ensure that all changes are positive and address what is best for the students and organization. Louis and Wahlstrom, [29], explain that principals play a major role in shaping the culture and leading the conversations that are associated with student learning.

Consequently, Anderson and Dexter, [8], state that the principal's leadership behavior contributes to the use of technology by teachers and students. A study directed by Dawson and Rakes [5] demonstrated that the principal's leadership behavior is a major influence on technology integration. It is the principal's leadership behavior that has often served as a predictor of the influence of technology on teaching and learning [8]. Because the principal's leadership behavior is a major influencer of technology integration on their campus, it has been suggested that principals must themselves have a general understanding of the technologies on campus and their potential in order to cultivate technology integration aligned to their campus visions. The principal's leadership behavior serves as an influencer and a role mode.

A principal's use of technology will transmit the importance of technology to both staff members and students. Holland and Moore-Steward [1] remarked that the principal needs to model and support technology applications in meaningful activities. It is doubtful that simply transferring poor approaches from pencil and paper worksheets to digital formats will bring about improved student achievement. Principals who are technology leaders comprehend that when properly used at schools, technology will enhance teaching and learning in the classroom.

Elementary principals are the technology leaders on their campuses; and as the main motivators of their faculty and students, they should be positive role models that use technologies that promotes learning and productivity on a daily or weekly basis. Elementary principals should continue to run both administrative and instructional tasks that affect students' needs and that are aligned with their campus mission, vision and goals. These leaders should continue to frequently monitor their students' academic progress whether at the local, state levels at software assessments.

In addition, elementary principals should continue to reach out and connect to all the stake holders via the various forms of social media. Social media like many forms of media creates a public forum for all stakeholders to view and learn about campus events and students' or teacher's accomplishments. It is an easily accessible medium that can be reached in a variety for formats such as on PCs, Macs, both Android and iMac tablets, and smart cellular phones.

Lastly, all elementary principals should continue to be motived risk takers and lifelong learners of a variety of technologies that can help them move forward their campus visions and student achievement. According to Dexter [30], it's very difficult to have technology implementations without a strong instructional focus. Therefore, they should not just be self-directed learners, but collaborators as well with their faculty, staff and students academic needs. Dexter further suggests a team-based leadership approach has positive implications for using technology to support teaching and learning. Thus, elementary principals should be able to reach out collaboratively in learning current or new technologies and become positive role models that share their knowledge and expertise with the school community. Louis and Wahlstrom [29] elaborate on the value of utilizing the principles of adult learning as a means of establishing the most effective organizational learning in schools. Technology as a tool is a powerful vehicle that has and can impact student learning when teachers and principals work collectively and collaboratively to build a professional community focused on shared leadership.

\section{REFERENCES}

[1] Holland, L. \& Moore-Steward, T. (2000). A different divide: preparing tech-savvy leaders. Retrieved on June 102018 fromhttp://www.acsa.orgpublications/pub_detail.cfm? leadership PubID=1323

[2] Eren, E. S., \& Kurt, A. A. (2011). Technological leadership behavior of elementary school principals in the process of supply and use of educational technologies. Education, 131(3), 625-636.

[3] Webber, C.F. (2003). New technologies and educative leadership. Journal of Educational Administration.41 (2), 


\section{pp. 119-123}

[4] Slowinski, J. (2003). Becoming a technologically savvy administrator. Teacher Librarian, 30(5), 25-29. Retrieved on September 11, 2006 from http://eric.uoregon.edu/ pdf/digests/ digest135.pdf

[5] Dawson, C., \& Rakes, G. (2003). The influence of principals' technology training on the integration of technology into schools. Journal of Research on Technology in Education, 36(1),29-49.http://dx.doi.org/10.1080/15391523.2003.1078 2401

[6] Gibson, I. W. (2002). PT3 and T3L-Teaching tomorrow's technology leaders: Preparing school leaders to use technology. Proceedings of SITE 2002: Society for Information Technology \& Teacher Education International Conference. Nashville, TN

[7] Afshari, M., Bakar, K.A., Luan, W. S., Samah, B. A. and Fooi, RS.(2008).School leadership and information communication technology. The Turkish Online Journal of Educational Technology - TO JET, 7(4).

[8] Anderson, R. E., \& Dexter, S. (2005). School technology leadership: An empirical investigation of prevalence and effect. Educational Administration Quarterly, 41(1), 49-82. http://dx.doi.org/10.1177/0013161X04269517

[9] Kruse, J., \& Buckmiller, T. (2015). Making the shift from school manager to instructional leader: Using the nature of technology framework as a tool for analysis. International Journal of Education, 7(1), 75-94.

[10] Kelley, B., Kinard, B. \& Hope, W. (1999). Perception of Training Needs: Principals' Use of Computer Technology in the School Environment. In J. Price et al. (Eds.), Proceedings of Society for Information Technology and Teacher Education International Conference 1999 (pp. 476-480). Chesapeake, VA: AACE.

[11] Schrum, L., Galizio, L., \& Ledesma, P. (2011). Educational leadership and technology integration: An investigation into preparation, experiences, and roles. Journal of School. 'Leadership, 21(2), 241-261.

[12] Hayashi, C. A., \& Fisher-Adams, G. (2015). Strengthening leadership preparation to meet the challenge of leading for learning in the digital age: Recommendations from alumni. Educational Leadership and Administration: Teaching and Program Development, 26(March), 51-67

[13] Garcia, A. (2013, October). Fundamental skills of the elementary principal as a technology leader. Paper presented at the Consortium of State Organizations for Texas Teacher Education (CSOTTE), San Antonio, TX.

[14] Knowles, Malcolm, and Associates. Andragogy in Action: Applying Modern Principles of Adult Learning. San Francisco: Jossey-Bass, 1984.

[15] Lieb, S.(1991). Principles of adult learning. Phoenix, AZ: Vision-South Mountain Community College. http://honolulu. hawaii.edu/intranet/committees/FacDevCo $\mathrm{m} /$ guidebk/teachtip/adults-2.htm

[16] Huang, H. (2002). Toward constructivism for adult learners in online learning environments. British Journal of Educational Technology,33(1),27-37.https://doi.org/10.111 $1 / 1467-8535.00236$
[17] Creswell, J.W. (2003). Research Design: Qualitative, Quantitative and Mixed Methods Approaches 2nd Edition. Thousand Oaks, CA: Sage Publications, Inc.

[18] Merriam, S. (1998). Qualitative research and case study applications in education. San Francisco: Jossey-Bass.

[19] Moustakas, C. (1994). Phenomenological research methods. Thousand Oaks, CA: Sage.

[20] Cohen, L., Manion, L., \& Morrison, K. (2007). Research Methods in Education (6th ed.). London and New York, NY: Routledge Falmer.

[21] Miles, M. B., \& Huberman, A. M. (1994). Qualitative Data Analysis: An Expanded Sourcebook. Thousand Oaks, CA: Sage Publications.

[22] Creswell, J.W. (2012). Educational research: Planning, conducting, and evaluating quantitative and qualitative research $\left(4^{\text {th }}\right.$ ed). Boston, MA: Pearson Education, Inc.

[23] Lincoln, Y. S., \& Guba, E. G. (1985). Naturalistic Inquiry. Beverly Hills, CA: Sage.

[24] Bloomberg, L. D., \& Volpe, M. (2012). Completing your qualitative dissertation: A road map from beginning to end (2nd ed.) Thousand Oaks, CA: Sage Publications.

[25] Texas Education Agency. (2018). PEIMS. Retrieved from https://tea.texas.gov/Reports and Data/Data Submission/P EIMS/PEIMS_Data_Standards/PEIMS_Data_Standards

[26] West, B. (2003). Building the Bridge to Effective Use of Technology. In A.D. Wheatley (Eds.), How to Ensure Ed/Tech is not Oversold and Underused (pp. 53-72). Lanham: Maryland: Scarecrow, Press, Inc.

[27] Garcia, A. (2009). The development of the elementary principal as a technology leader (Doctoral dissertation, University of Texas- Pan American). ProQuest.

[28] Dempsey, D.F. (1999). The Principal Push for Technology. High School Magazine. 7(1), 30-33.

[29] Louis, K. S., \& Wahlstrom, K. (2011). Principals as cultural leaders. Kappan. 92(5), 52-56.

[30] Dexter, S. (2011). School technology leadership: Artifacts in systems of practice. Journal of School Leadership. 21, 166-189. 